Особенности взаимосвязей хемилюминесцентной и ферментативной активности нейтрофилов крови у больных с разной степенью тяжести внебольничной пневмонии

\author{
А.А.Савиенко ${ }^{1,2}$, Ю.И.Гринштейн ${ }^{2}$, Л.Б.Дресвянкина ${ }^{1}$, А.И.Аристов ${ }^{2}$ \\ 1 - ФГБНУ «НИИ медицинских проблем Севера»: 660022, Красноярск, ул. Партизана Железняка, 3г; \\ 2 - ГБОУ ВПО «Красноярский государственный медицинский университет имени профессора В.Ф.Войно-Ясенецкого» Министерства здравоохранения РФ: \\ 660022, Красноярск, ул. Партизана Железняка, 1
}

\title{
Резюме
}

Цель. Изучение взаимосвязи ферментативной и хемилюминесцентной активности нейтрофилов крови у больных с тяжелым и среднетяжелым течением внебольничной пневмонии (ВП). Материалы и методы. Обследованы пациенты с ВП средней степени тяжести $(n=48)$ и тяжелой $(n=40)$ в 1-е сутки госпитализации. С помощью хемилюминесцентного анализа определены уровни синтеза первичных и вторичных активных форм кислорода. С помощью биолюминесцентного метода исследованы уровни активности НАД(Ф)-зависимых дегидрогеназ в нейтрофилах. Результаты и обсуждение. Установлено, что у больных ВП повышен уровень «респираторного взрыва» в нейтрофильных гранулоцитах. Только у больных с тяжелой степенью ВП в клетках повышена интенсивность терминальных реакций анаэробного гликолиза и цикла трикарбоновых кислот. Независимо от тяжести ВП в нейтрофильных гранулоцитах наблюдается повышенная активность липидного анаболизма и отток субстратов с «лимонного» цикла через НАДН-зависимую глутаматдегидрогеназу. Заключение. С помощью канонического анализа установлено, что у больных ВП нарушаются метаболические механизмы формирования «респираторного взрыва» нейтрофилов.

Ключевые слова: внебольничная пневмония, нейтрофильные гранулоциты, хемилюминесценция, активные формы кислорода, метаболизм, активность ферментов.

DOI: 10.18093/0869-0189-2015-25-6-685-692

\section{Relationship between chemiluminescent and enzymatic activity of blood neutrophils interactions in patients with community- acquired pneumonia}

\author{
A.A.Savchenko ${ }^{1,2}$, Yu.I.Grinshteyn ${ }^{2}$, L.B.Dresvyankina ${ }^{1}$, A.I.Aristov ${ }^{2}$ \\ 1 - Federal Research Institute of Medical Problems of the North, 3g, Partizana Zheleznyaka str., Krasnoyarsk, 660022, Russia; \\ 2 - V.F.Voyno-Yasenetskiy Krasnoyarsk State Medical University, Healthcare Ministry of Russia; 1, Partizana Zheleznyaka str., Krasnoyarsk, 660022, Russia
}

\section{Summary}

The aim of the study was to investigate enzymatic and chemiluminescent activity in blood neutrophils of patients with moderate and severe community-acquired pneumonia (CAP). Methods. The study involved 48 patients with moderate CAP and 40 patients with severe CAP; they were examined on admission. Synthesis of primary and secondary reactive oxygen species (ROS) was evaluated using the chemiluminescence assay. Neutrophil NAD(P)-dependent dehydrogenase activity was assessed using the bioluminescent method. Results. The «respiratory burst» was found in neutrophils of CAP patients. Terminal reactions of the anaerobic glycolysis and the tricarbonic acid cycle were intensified in patients with severe CAP only. Increased lipid anabolism activity and substrate outflow from the tricarbonic acid cycle via NADH-dependent glutamate dehydrogenase were shown regardless of CAP severity. The canonical analysis showed abnormalities of metabolic mechanisms of the «respiratory burst» in blood neutrophils in CAP. Conclusion. The metabolic disorders and «respiratory burst» intensity in CAP arize the need for pathogenic correction. High NADH-dependent dehydrogenase activity and lower chemiluminescent activity in blood neutrophils could be used as additional markers of severe course of CAP. Key words: community-acquired pneumonia, neutrophilic granulocytes, chemiluminescence, reactive oxygen species, metabolism, enzyme activities.

Несмотря на постоянное совершенствование методов диагностики, использования в терапии современных высокоэффективных антибактериальных препаратов внебольничная пневмония (ВП) занимает одно из ведущих мест в структуре причин смерти в мире и 1-е - среди инфекционных заболеваний [1, 2]. При этом тяжесть течения ВП и исход заболевания зависят не только от возбудителя, но и от состояния иммунной системы человека.

Нейтрофильные гранулоциты составляют 1-ю линию неспецифической противомикробной защиты. Обладая высокой реактивностью, они способны быстро функционально перестраиваться в ответ на многочисленные сигналы о дестабилизации внутренней среды, определяя процесс развития воспаления [3-5]. Скорость мобилизации нейтрофилов определяется их способностью к быстрому развитию метаболических процессов, сопровождающихся развитием «кислородного взрыва» с последующей продукцией активных форм кислорода (АФК), обладающих цитотоксическим эффектом [6, 7]. Вместе с тем взаимоотношения метаболического статуса нейтрофилов и продукции АФК у больных ВП остаются недостаточно изученными. Поэтому одним из перспективных направлений является изучение влияния активности основных ферментативных реак- 
ций, составляющих энергетическое и пластическое звенья метаболизма клетки, на интенсивность «респираторного взрыва» нейтрофильных гранулоцитов. Исследование метаболических механизмов функциональной активности гранулоцитов позволит охарактеризовать процессы жизнедеятельности клетки в условиях воспаления и выявить дополнительные маркеры степени тяжести ВП в ее дебюте.

Целью исследования явилось изучение взаимосвязи ферментативной и хемилюминесцентной активности нейтрофилов крови у больных с тяжелым и среднетяжелым течением ВП.

\section{Материалы и методы}

В исследование были включены пациенты $(n=88$ : 69 \% мужчин и $31 \%$ женщин; возраст 18-60 лет), госпитализированные в пульмонологическое отделение МБУЗ «Городская клиническая больница № 20» (Красноярск), диагноз при поступлении - ВП. Диагноз ВП устанавливался согласно Российским национальным рекомендациям по ВП (2010), и рекомендациям Американского торакального общества (ATS) / Американского общества инфекционистов (IDSA) $(2005,2007)[1,8,9]$. Степень тяжести определялась клинико-лабораторными и инструментальными критериями [10], а также по шкале о решении о месте лечения больных ВП (CURB-65) и соответствовала Международной классификации болезней 12-го пересмотра. Диагностирована средняя $(n=48)$ и тяжелая $(n=40)$ степень ВП. Поражение легочной ткани при тяжелой ВП в 72 \% случаев было представлено вовлечением доли легкого, в 15,5 \% - полисегментарным двусторонним поражением, в 4,7 \% - тотальным или субтотальным односторонним поражением легких, у 7,8 \% - сегментарным поражением легочной ткани. При ВП средней степени тяжести преобладало сегментарное поражение легких $(79,6$ \%), в 1,1 \% случаев отмечалось полисегментарное двустороннее поражение легочной ткани, и только в $18,2 \%$ - долевое поражение. В 1-е сутки госпитализации больным проводился забор крови для изучения хемилюминесцентной и метаболической активности нейтрофильных гранулоцитов. В качестве контроля обследованы здоровые лица $(n=125)$ аналогичного возраста.

Исследование выполнено в соответствии со стандартами надлежащей клинической практики и принципами Хельсинкской декларации (2001). Протокол исследования одобрен локальным этическим комитетом. До включения в исследование у всех участников было получено письменное информированное согласие.

Нейтрофильные гранулоциты выделялись из цельной гепаринизированной крови центрифугированием в двойном градиенте плотности фиколлурографина: $p=1,077$ г / $\mathrm{cm}^{3}-$ для отделения лимфоцитов; $p=1,119$ г / см ${ }^{3}-$ для выделения нейтрофилов. Оценка люцигенин- и люминол-зависимой спонтанной и зимозан-индуцированной хемилюминесценции осуществлялась в течение 90 мин на 36-канальном хемилюминесцентном анализаторе CL3606 (Россия) [4]. Определялись следующие характеристики: время выхода на максимум ( $\left.\mathrm{T}_{\max }\right)$, максимальное значение интенсивности $\left(\mathrm{I}_{\max }\right)$, а также площадь под кривой $(\mathrm{S})$ хемилюминесценции. Усиление зимозан-индуцированной хемилюминесценции оценивалось отношением площади индуцированной хемилюминесценции к площади спонтанной $\left(\mathrm{S}_{\text {инд. }} / \mathrm{S}_{\text {спонт. }}\right)$ и определялось как индекс активации. Для проведения биолюминесцентного анализа активности глюкозо-6-фосфатдегидрогеназы (ГбФДГ), глицерол-3-фосфатдегидрогеназы (ГЗФДГ), малик-фермента (НАДФМДГ), НАДи НАДН-зависимой реакции лактатдегидрогеназы (ЛДГ и НАДН-ЛДГ), НАД- и НАДН-зависимоЙ реакции малатдегидрогеназы (МДГ и НАДН-МДГ), НАДФ- и НАДФН-зависимой глутаматдегидрогеНазЫ (НАДФГДГ и НАДФН-ГДГ), НАД- и НАДНзависимой глутаматдегидрогеназы (НАДГДГ и НАДНГДГ), НАД- и НАДФ-зависимых изоцитратдегидрогеназ (НАДИЦДГ и НАДФИЦДГ, соответственно) и глутатионредуктазы (ГР) нейтрофильные гранулоциты разрушали путем осмотического лизиса с добавлением 2 мМ дитиотреитола [11]. Активность НАД(Ф)-зависимых дегидрогеназ выражалась в ферментативных единицах на $10^{4}$ клеток, где $1 \mathrm{E}=1$ мкмоль / мин [12]. Исследование проводилось на ферментативном препарате НАД(Ф): ФМНоксидоредуктаза-люцифераза из Photobacterium leiognathi (получен в Институте биофизики Сибирского отделения РАН, Красноярск). Все исследования выполнены с информированного согласия обследуемых и в соответствии с этическими нормами Хельсинкской декларации (2001).

Описание выборки производилось с помощью подсчета медианы и интерквартильного размаха в виде 25 -го и 75-го процентилей $\left(\mathrm{C}_{25}\right.$ и $\mathrm{C}_{75}$ соответственно). Достоверность различий между показателями оценивалась по непараметрическому критерию Манна-Уитни. Для оценки комплексной взаимосвязи между показателями хемилюминесценции нейтрофильных гранулоцитов и активностью ферментов использовался канонический анализ с подсчетом коэффициента канонической корреляции (R) и канонических весов коррелируемых параметров. Статистическая значимость коэффициента канонической корреляции оценивалась по $\chi^{2}$. Статистический анализ осуществлялся в пакете прикладных программ Statistica 8.0 (StatSoft Inc., 2007).

\section{Результаты и обсуждение}

При исследовании параметров спонтанной люцигенин-зависимой хемилюминесценции нейтрофильных гранулоцитов у больных ВП обнаружено, что независимо от степени тяжести заболевания снижается $\mathrm{T}_{\max }$ относительно контрольных показателей, a также повышается $\mathrm{I}_{\max }$ и $\mathrm{S}$ спонтанной хемилюминесценции (табл. 1). Только у больных со средней степенью тяжести ВП относительно контрольных значений понижается $\mathrm{T}_{\max }$ зимозан-индуцированной 
Люцигенин-зависимая хемилюминесцентная активность нейтрофильных гранулоцитов у больных с разной тяжестью ВП (медиана (Мe), $\left.C_{25}-C_{75}\right)$

Table 1

Lucigen-dependent chemiluminescence of neutrophil granulocytes in patients with community-acquired pneumonia (Me, $\left.\mathrm{C}_{25}-\mathrm{C}_{75}\right)$

\begin{tabular}{|c|c|c|c|c|c|c|}
\hline \multirow[t]{2}{*}{ Показатели } & \multicolumn{2}{|c|}{ Контроль, $n=125$} & \multicolumn{2}{|c|}{ Средняя степень тяжести, $n=48$} & \multicolumn{2}{|c|}{ Тяжелая степень, $n=40$} \\
\hline & Me & $\mathrm{C}_{25}-\mathrm{C}_{75}$ & Me & $\mathrm{C}_{25}-\mathrm{C}_{75}$ & Me & $\mathrm{C}_{25}-\mathrm{C}_{75}$ \\
\hline \multicolumn{7}{|c|}{ Спонтанная хемилюминесценция } \\
\hline \multirow[t]{2}{*}{$T_{\max }, C$} & 2552 & $1759-3547$ & 1476 & $1093-2240$ & 1803 & $984-2243$ \\
\hline & & & $p_{1}<0,001$ & & $p_{1}<0,001$ & \\
\hline \multirow[t]{2}{*}{$I_{\max }$, o. e. $\times 10^{3}$} & 6,79 & $2,58-14,28$ & 17,82 & $10,08-51,50$ & 13,35 & $9,25-32,63$ \\
\hline & & & $p_{1}<0,001$ & & $p_{1}<0,001$ & \\
\hline \multirow[t]{2}{*}{ S, o. e. $\times c \times 10^{5}$} & 3,05 & $1,04-9,51$ & 14,93 & $6,13-28,10$ & 12,40 & $5,29-23,93$ \\
\hline & & & $p_{1}<0,001$ & & $p_{1}<0,001$ & \\
\hline \multicolumn{7}{|c|}{ Зимозан-индуцированная хемилюминесценция } \\
\hline \multirow[t]{2}{*}{$T_{\max }, C$} & 2029 & $1618-2647$ & 1444 & $1086-1992$ & 1776 & $1108-2495$ \\
\hline & & & $p_{1}=0,001$ & & & \\
\hline \multirow[t]{2}{*}{$I_{\max }$, o. e. $\times 10^{3}$} & 11,16 & $7,63-27,68$ & 39,67 & $17,24-56,73$ & 20,44 & $9,24-38,70$ \\
\hline & & & $p_{1}<0,001$ & & $p_{1}=0,023$ & \\
\hline \multirow[t]{2}{*}{ S, o. e. $\times c \times 10^{6}$} & 5,65 & $2,95-15,49$ & 17,55 & $8,50-49,84$ & 13,67 & $8,09-28,99$ \\
\hline & & & $p_{1}=0,002$ & & $p_{1}=0,002$ & \\
\hline \multirow[t]{2}{*}{$\mathbf{S}_{\text {инд. }} / \mathbf{S}_{\text {спонт. }}$} & 1,77 & $1,11-3,22$ & 1,28 & $0,70-2,01$ & 1,07 & $0,75-2,05$ \\
\hline & & & $p_{1}=0,018$ & & $p_{1}=0,005$ & \\
\hline
\end{tabular}

Примечание: $p_{1}$ - статистически значимые различия с контрольными показателями.

Note. $p_{1}$, statistically significant difference between community-acquired pneumonia patients and controls.

люцигенин-зависимой хемилюминесценции. Независимо от степени тяжести заболевания у больных ВП значительно повышаются $\mathrm{I}_{\max }$ и $\mathrm{S}$ индуцированной хемилюминесценции, а также понижается величина индекса активации.
Известно, что люцигенин окисляется и люминесцирует только под влиянием супероксид-радикала, который определяется как первичная АФК и синтезируется в системе НАДФН-оксидазы [3, 13]. Следовательно, исследование люцигенин-зависимой хе-

Таблица 2

Люминол-зависимая хемилюминесцентная активность нейтрофильных гранулоцитов у больных с разной степенью тяжести ВП (Ме, $\left.C_{25}-C_{75}\right)$ Table 2 Luminol-dependent chemiluminescence of neutrophil granulocytes in patients with community-acquired pneumonia (Me, $\left.\mathrm{C}_{25}-\mathrm{C}_{75}\right)$

\begin{tabular}{|c|c|c|c|c|c|c|}
\hline \multirow[t]{2}{*}{ Показатели } & \multicolumn{2}{|c|}{ Контроль, $n=125$} & \multicolumn{2}{|c|}{ Средняя степень тяжести, $n=48$} & \multicolumn{2}{|c|}{ Тяжелая степень, $n$ = 40} \\
\hline & Me & $\mathrm{C}_{25}-\mathrm{C}_{75}$ & Me & $\mathrm{C}_{25}-\mathrm{C}_{75}$ & Me & $\mathrm{C}_{25}-\mathrm{C}_{75}$ \\
\hline \multicolumn{7}{|c|}{ Спонтанная хемилюминесценция } \\
\hline $\mathrm{T}_{\max }, \mathrm{C}$ & 966 & $587-1514$ & 805 & $434-1172$ & 835 & $533-1744$ \\
\hline \multirow{3}{*}{$I_{\max }$, o. e. $\times 10^{3}$} & 7,98 & $3,26-21,01$ & 55,74 & $32,35-92,19$ & 31,12 & $17,38-65,20$ \\
\hline & & & $p_{1}<0,001$ & & $p_{1}<0,001$ & \\
\hline & & & & & $p_{2}=0,036$ & \\
\hline \multirow[t]{3}{*}{ S, o. e. $\times \mathrm{c} \times 10^{5}$} & 2,66 & $1,12-7,18$ & 35,15 & $21,00-50,68$ & 21,0 & $12,55-43,30$ \\
\hline & & & $p_{1}<0,001$ & & $p_{1}<0,001$ & \\
\hline & & & & & $p_{2}=0,029$ & \\
\hline \multicolumn{7}{|c|}{ Зимозан-индуцированная хемилюминесценция } \\
\hline \multirow[t]{2}{*}{$\mathbf{T}_{\max }, \mathrm{C}$} & 1098 & $796-1463$ & 806 & $619-1168$ & 865 & $561-1334$ \\
\hline & & & $p_{1}<0,001$ & & $p_{1}=0,020$ & \\
\hline \multirow[t]{2}{*}{$I_{\max }$, o. e. $\times 10^{3}$} & 17,48 & $7,02-34,62$ & 113,32 & $52,84-130,44$ & 71,42 & $38,74-118,08$ \\
\hline & & & $p_{1}<0,001$ & & $p_{1}<0,001$ & \\
\hline \multirow[t]{2}{*}{ S, o.e. $\times c \times 10^{6}$} & 5,47 & $1,97-12,63$ & 56,30 & $35,30-94,71$ & 46,55 & $23,90-79,55$ \\
\hline & & & $p_{1}<0,001$ & & $p_{1}<0,001$ & \\
\hline $\mathbf{S}_{\text {инд. }} / \mathbf{S}_{\text {спонт. }}$ & 1,74 & $1,34-2,50$ & 1,66 & $1,17-2,85$ & 1,87 & $1,36-3,30$ \\
\hline
\end{tabular}

Примечание: статистически значимые различия: $p_{1}$ - с контрольными показателями; $p_{2}$ - с показателями больных со средней тяжестью заболевания. Notes. $p_{1}$, statistically significant difference between community-acquired pneumonia patients vs. controls; $p_{2}$, statistically significant between patients with moderate vs. severe communityacquired pneumonia. 
милюминесценции нейтрофильных гранулоцитов позволяет охарактеризовать состояние активности НАДФН-оксидазы в нейтрофильных гранулоцитах у больных ВП разной степени тяжести. В то же время бактерицидная активность нейтрофилов также определяется и уровнем синтеза вторичных форм кислорода $[4,14,15]$. Для оценки суммарного уровня синтеза и первичных, и вторичных АФК определялись показатели люминол-зависимой хемилюминесценции.

Установлено, что у больных ВП значительно повышается максимум и $\mathrm{S}$ спонтанной люминол-зависимой хемилюминесценции относительно контрольных значений (табл. 2). Однако у больных с тяжелой степенью заболевания данное повышение хемилюминесцентных показателей менее выражено, чем при средней степени тяжести ВП. Независимо от тяжести заболевания у больных относительно контрольного диапазона снижается $\mathrm{T}_{\max }$ зимозаниндуцированной хемилюминесценции и повышаются $\mathrm{I}_{\max }$ И $\mathrm{S}$.

Анализ результатов хемилюминесцентного анализа позволяет охарактеризовать особенности синтеза АФК нейтрофильными гранулоцитами в зависимости от степени тяжести ВП. Установлено, что уровень синтеза первичных АФК нейтрофилами крови у больных незначительно зависит от степени тяжести ВП: снижается $\mathrm{T}_{\max }$ спонтанной хемилюминесценции, повышается $\mathrm{I}_{\max }$ и $\mathrm{S}$ как спонтанной, так и зимозан-индуцированной люцигенин-зависимой хемилюминесценции. Снижение индекса активации люцигенин-зависимой хемилюминесценции отражает недостаточность активации НАДФН-оксидазы при дополнительной индукции «респираторного взрыва». Единственной особенностью кинетики синтеза первичных АФК нейтрофилами у больных со средней степенью тяжести ВП является снижение $\mathrm{T}_{\max }$ индуцированной хемилюминесценции.

Более выраженные особенности в зависимости от степени тяжести ВП выявляются у больных при синтезе вторичных АФК нейтрофилами крови. Показано, что при средней и тяжелой степени заболевания повышается $\mathrm{I}_{\max }$ и $\mathrm{S}$ спонтанной люминол-зависимой хемилюминесценции, но при тяжелой степени ВП это повышение менее выражено, чем при средней степени тяжести. В то же время при дополнительной индукции «респираторного взрыва» с помощью зимозана особенностей в уровне синтеза вторичных АФК не обнаружено. У больных ВП независимо от степени тяжести снижается $\mathrm{T}_{\max }$, повышается $\mathrm{I}_{\max }$ и $\mathrm{S}$ зимозан-индуцированной люминол-зависимой хемилюминесценции.

Как уже отмечалось, функциональные проявления различных клеток иммунной системы значительно зависят от состояния их метаболизма $[4,16]$. В связи с этим исследованы уровни активности НАД- и НАДФ-зависимых дегидрогеназ нейтрофильных гранулоцитов у больных ВП в зависимости от степени тяжести заболевания. Обнаружено, что только у больных ВП тяжелой степени повышается активность НАДН-ЛДГ (см. рисунок, А) и МДГ (см. рисунок, В). Независимо от степени тяжести заболевания у больных в нейтрофильных гранулоцитах крови повышается активность НАДФМДГ (см. рисунок, С) и НАДН-ГДГ (см. рисунок, D).

Исследуемые оксидоредуктазы занимают ключевые позиции основных метаболических путей. Следовательно, их анализ позволяет не только оценить уровни активности отдельных ферментов, но и опре-
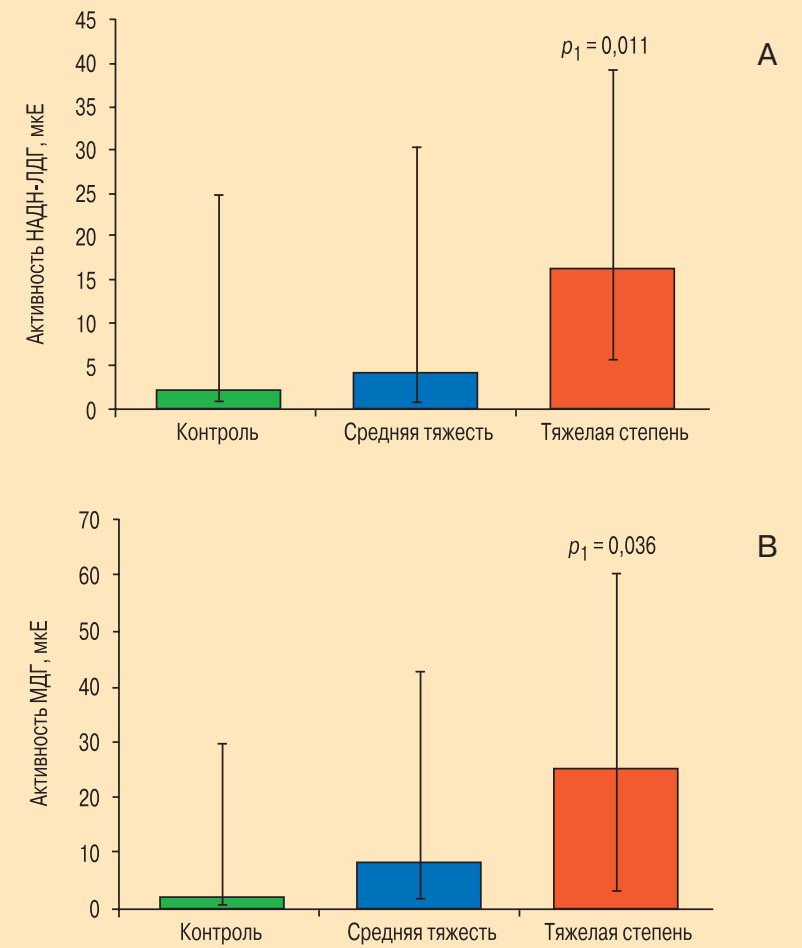

B
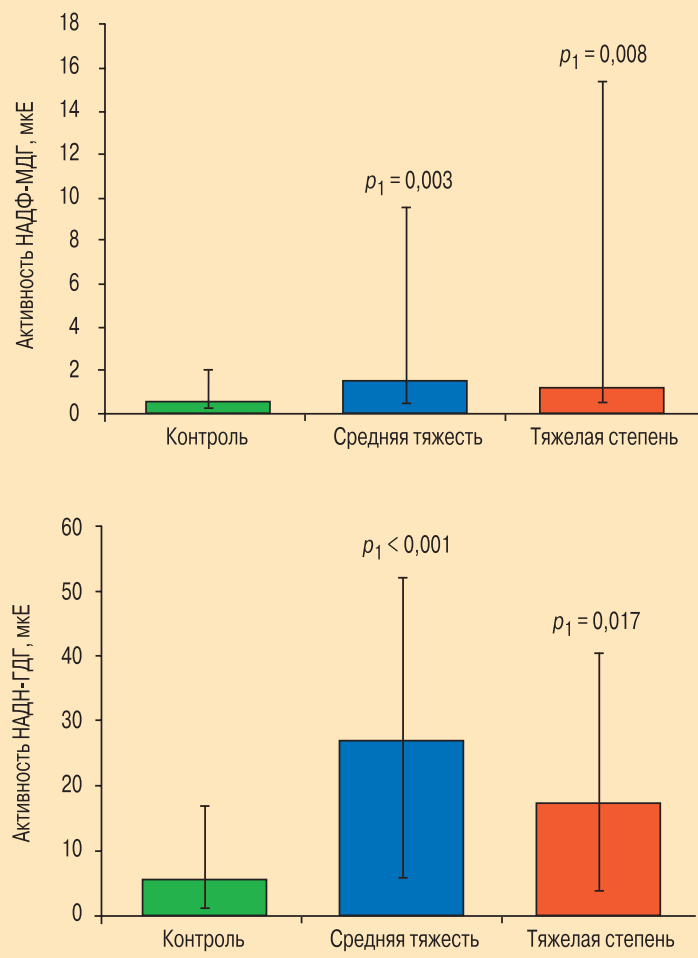

Рисунок. Активность НАД- и НАДФ-зависимых дегидрогеназ в нейтрофилах крови у больных с разной степенью тяжести ВП Figure. Neutrophil NAD- and NADPh-dependent dehydrogenases activity in patients with community-acquired pneumonia 
делить интенсивность метаболических путей или циклов, а также реактивность метаболических процессов в целом. Так, особенностью метаболизма нейтрофилов у больных с тяжелой степенью ВП является повышение активности НАДН-ЛДГ и МДГ. Активностью анаэробной реакции ЛДГ (НАДНЛДГ) характеризуется состояние терминальных реакций анаэробного гликолиза, который является основным энергопродуцирующим процессом для нейтрофильных гранулоцитов [12, 17]. МДГ - фермент цикла трикарбоновых кислот, который является ключевым амфиболическим процессом в клетках, осуществляющим метаболическую поддержку функционирования дыхательной цепи в митохондриях. При этом роль митохондрий в реализации функциональной активности и запрограммированной гибели нейтрофилов активно изучается [18, 19]. Независимо от степени тяжести ВП в нейтрофилах крови больных повышаются уровни активности НАДФ МДГ и НАДН-ГДГ, характеризующие шунтирование медленных реакций и интенсивность НАДН-зависимого оттока субстратов с «лимонного» цикла [12].

С помощью канонического анализа исследованы особенности взаимосвязи между показателями хемилюминесценции нейтрофильных гранулоцитов и внутриклеточной активностью ферментов. Выбор канонического анализа связан с тем, что данный метод позволяет оценить взаимосвязь 2 наборов показателей: показатели хемилюминесценции и активность внутриклеточных ферментов. В качестве показателей хемилюминесценции нейтрофилов выбраны $\mathrm{T}_{\max }, \mathrm{I}_{\max }$ И $\mathrm{S}$ хемилюминесценции. Обнаружено, что у лиц контрольной группы значимый вклад в каноническую взаимосвязь с показателями спонтанной люцигенин-зависимой хемилюминес- ценции вносят все исследуемые ферменты нейтрофилов (табл. 3). При этом наиболее значимый вклад, исходя из величины канонических весов, вносят НАДФГДГ $(-0,792)$, НАДФМДГ $(0,932)$ и НАДНЛДГ $(0,702)$. Однако у больных со средней и тяжелой степенью ВП статистически значимые значения канонических коэффициентов корреляции и $\chi^{2}$ достигаются только при наборе уровней активности ферментов, указанных в табл. 3. У больных со средней степенью ВП наиболее значимый вклад в каноническую корреляцию с показателями спонтанной люцигенин-зависимой хемилюминесценции вносят уровни активности НАДИЦДГ $(1,071)$, ГЗФДГ $(-0,842)$ и НАДФИЦДГ $(0,788)$. При тяжелой степени тяжести ВП наиболее значимыми являются уровни активности НАДФН-ГДГ $(0,919)$, НАДФМДГ $(-0,836)$ и ГР $(-0,762)$.

Индукция «дыхательного взрыва» зимозаном стимулирует интенсивность ряда метаболических процессов нейтрофильных гранулоцитов [4], что соответственно должно привести к изменению зависимости хемилюминесценции от активности внутриклеточных процессов. У лиц контрольной группы в канонической зависимости зимозан-индуцированной люцигенин-зависимой хемилюминесценции принимают участие все исследуемые ферменты. Наибольший вклад оказывают уровни активности НАДФМДГ $(1,745)$, НАДИЦДГ $(1,408)$ и ГбФДГ $(-1,075)$. При средней и тяжелой степени ВП статистически значимые значения коэффициентов канонической корреляции и $\chi^{2}$ достигнут только при наборе ферментов, указанных в табл. 3. У больных со средней степенью ВП наиболее значимый вклад в каноническую корреляцию внесен НАДФН-ГДГ $(-0,625)$, НАДФМДГ $(0,610)$ и МДГ $(-0,594)$, тогда

Таблица 3

Каноническая корреляция показателей хемилюминесценции нейтрофильных гранулоцитов с уровнем активности НАД- и НАДФ-зависимых дегидрогеназ

Table 3

Canonic correlation between neutrophil chemiluminescence and NAD- and NADPh-dependent dehydrogenase activity

\begin{tabular}{|c|c|c|c|c|}
\hline $\begin{array}{c}\text { Группа обсле- } \\
\text { дуемых (степень } \\
\text { тяжести ВП) }\end{array}$ & Ферменты & Canonical $\mathbf{R}$ & $\chi^{2}$ & $p$ \\
\hline \multicolumn{5}{|c|}{ Спонтанная люцигенин-зависимая хемилюминесценция } \\
\hline Контроль & Все исследуемые ферменты & 0,99 & 86,72 & $<0,001$ \\
\hline Средняя & ГЗФДГ, НАДФМДГ, НАДФИЦДГ, МДГ, НАДИЦДГ & 0,87 & 28,49 & 0,019 \\
\hline Тяжелая & ГбФДГ, НАДФМДГ, НАДФГДГ, МДГ, НАДГДГ, НАДН-ЛДГ, НАДН-МДГ, ГР, НАДН-ГДГ, НАДФН-ГДГ & 0,99 & 57,28 & 0,002 \\
\hline \multicolumn{5}{|c|}{ Зимозан-индуцированная люцигенин-зависимая хемилюминесценция } \\
\hline Контроль & Все исследуемые ферменты & 0,99 & 72,12 & 0,003 \\
\hline Средняя & ГЗФДГ, НАДФМДГ, НАДФИЦДГ, НАДН-ЛДГ, НАДН-МДГ, НАДФН-ГДГ & 0,87 & 32,84 & 0,017 \\
\hline Тяжелая & ЛДГ, НАДФМДГ, НАДФГДГ, МДГ, НАДГДГ, НАДН-ЛДГ, НАДН-МДГ, НАДН-ГДГ, НАДФН-ГДГ & 0,96 & 46,21 & 0,012 \\
\hline \multicolumn{5}{|c|}{ Спонтанная люминол-зависимая хемилюминесценция } \\
\hline Контроль & Все исследуемые ферменты & 0,78 & 114,80 & $<0,001$ \\
\hline Средняя & ГбФДГ, ЛДГ, НАДГДГ, НАДИЦДГ, НАДН-ЛДГ, НАДН-МДГ & 0,67 & 19,88 & 0,339 \\
\hline Тяжелая & НАДФМДГ, НАДФГДГ, НАДФИЦДГ, МДГ, НАДГДГ, НАДН-ЛДГ, НАДН-МДГ, ГР, НАДН-ГДГ, НАДФН-ГДГ & 0,97 & 46,66 & 0,027 \\
\hline \multicolumn{5}{|c|}{ Зимозан-индуцированная люминол-зависимая хемилюминесценция } \\
\hline Контроль & Все исследуемые ферменты & 0,84 & 116,55 & $<0,001$ \\
\hline Средняя & ГСФДГ, ГЗФДГ, НАДФМДГ, НАДФИЦДГ, МДГ, НАДН-МДГ, ГР & 0,76 & 33,04 & 0,046 \\
\hline Тяжелая & ГбФДГ, НАДФГДГ, НАДФИЦДГ, НАДГДГ, НАДИЦДГ, НАДН-ЛДГ, НАДН-МДГ, ГР & 0,86 & 26,47 & 0,330 \\
\hline
\end{tabular}


как при тяжелой степени ВП - НАДФГДГ $(1,145)$, НАДИЦДГ $(-0,870)$ и ГбФДГ $(-0,791)$.

При исследовании канонической корреляции между показателями спонтанной люминол-зависимой хемилюминесценции и активности внутриклеточных ферментов обнаружено, что у лиц контрольной группы в системе данной взаимосвязи принимают участие все исследуемые ферменты, из которых наибольший вклад оказывают уровни активности НАДФМДГ $(0,842)$, МДГ $(0,660)$ и ЛДГ (0,512). При средней степени тяжести ВП статистическая значимость канонической корреляции показателей спонтанной люминол-зависимой хемилюминесценции нейтрофилов с уровнем активности их ферментов отсутствует. Для данной группы обследуемых в табл. 3 указан набор ферментов, при котором получен наиболее высокий уровень коэффициента канонической корреляции и $\chi^{2}$. При тяжелой степени ВП статистически значимые значения коэффициента канонической корреляции и $\chi^{2}$ достигнут только при наборе ферментов, указанных в табл. 3, среди которых наибольший вес вносят НАДФН-ГДГ $(0,919)$, НАДФМДГ $(-0,836)$ и ГР $(-0,762)$.

В канонической зависимости между показателями индуцированной люминол-зависимой хемилюминесценции нейтрофилов лиц контрольной группы и активностью ферментов участвуют все исследуемые НАД(Ф)-зависимые дегидрогеназы, из которых наибольший вес вносят НАДФИЦДГ $(1,084)$, ЛДГ $(-0,947)$ и МДГ $(-0,873)$. При средней степени ВП статистически значимых значений коэффициент канонической корреляции и $\chi^{2}$ достигнут только при наборе ферментов, указанных в табл. 3, среди которых наибольший вес вносят ГР $(0,860)$, НАДФМДГ $(-0,701)$ и НАДН-МДГ $(-0,505)$. При тяжелой степени ВП статистическая значимость канонической корреляции показателей спонтанной люминол-зависимой хемилюминесценции нейтрофилов с уровнем активности их ферментов отсутствует. Для данной группы обследуемых в табл. 3 указан набор ферментов, при котором получен наиболее высокий уровень коэффициента канонической корреляции и $\chi^{2}$.

Безусловно, интенсивность «респираторного взрыва» нейтрофилов должна определяться состоянием их метаболизма. Активность НАДФ-оксидазы связана с зависимостью от уровня синтеза НАДФН в ряде метаболических процессов [20]. Уровень синтеза вторичных АФК зависит от активности антиоксидантной системы и уровня энергетических процессов в клетке. Действительно, исходя из результатов канонического анализа у здоровых лиц, уровень синтеза как первичных, так и вторичных АФК нейтрофилами зависит преимущественно от активности НАДФ-зависимых дегидрогеназ и энергопродуцирующих процессов. Ранее отмечена зависимость активности НАДФН-оксидазы от состояния пентозофосфатного цикла [20]. Однако появились исследования, в которых отмечена взаимосвязь синтеза супероксид-радикала с активностью НАДФМДГ и НАДФИЦДГ и ряда других ферментов $[13,20]$. Обнаружено, что наибольший вклад в каноническую зависимость с показателями спонтанной и индуцированной люцигенин- и люминол-зависимой хемилюминесценции нейтрофилов вносят такие НАДФ-зависимые ферменты, как НАДФМДГ, НАДФГДГ, НАДФИЦДГ и ГбФДГ. Можно констатировать, что метаболические процессы нейтрофилов в целом определяют функциональные возможности клеток и, в частности, интенсивность хемилюминесцентной реакции. При этом вклад исследуемых оксидоредуктаз (в виде продуктов ферментативных реакций и регуляторных процессов) в синтез первичных и вторичных АФК может различаться в зависимости от состояния метаболических процессов и функциональной активности нейтрофилов. Показательным является изменение знака канонических весов наиболее значимых ферментов канонической зависимости спонтанной и зимозан-индуцированной люминол-зависимой хемилюминесценции у здоровых людей. В состоянии относительного покоя метаболизм нейтрофилов наиболее стабилен, отсутствуют конкурентные взаимодействия между пластическими и энергетическими процессами, соответственно вклад ферментов и пластического, и энергетического профиля в уровень синтеза первичных и вторичных АФК положителен. При стимуляции «респираторного взрыва» (при воздействии опсонизированного зимозана) в нейтрофилах развиваются конкурентные взаимодействия между пластическими и энергетическими реакциями за субстрат, в результате которых меняется вклад (становится отрицательным) ферментов энергетического профиля (ЛДГ и МДГ) в каноническую взаимосвязь с показателями хемилюминесцентной реакции.

При развитии инфекционно-воспалительных процессов модуляция функциональной активности нейтрофилов реализуется через их метаболическую систему, что и выражается в изменении канонической зависимости между показателями хемилюминесценции нейтрофилов и активностью исследуемых ферментов. Особенностью канонической корреляции между показателями хемилюминесценции нейтрофилов и активностью их внутриклеточных ферментов у больных ВП является то, что для получения статистически значимой канонической взаимосвязи используется не весь набор исследуемых ферментов. В зависимости от тяжести ВП и хемилюминесцентной реакции формируется свой характерный набор оксидоредуктаз. Более того, у пациентов с ВП средней степени каноническая зависимость между активностью ферментов и показателями спонтанной люминол-зависимой хемилюминесценции, а также у больных ВП тяжелой степени взаимосвязи активности ферментов с показателями индуцированной люминол-зависимой хемилюминесценции не обнаружено. Можно предположить, что подобные особенности канонической зависимости определяются нарушениями в метаболизме нейтрофилов, которые в т. ч. реализуются и в дискоординации пластических и энергетических процессов между собой и с ферментами, участвующими в системе «рес- 
пираторного взрыва». У больных ВП расширен список ферментов энергетического профиля с высоким уровнем канонических весов. Также в число наиболее значимых ферментов включена ГР. Однако если у больных со средней степенью тяжести ВП данный фермент проявляет положительное каноническое взаимодействие с показателями индуцированной люминол-зависимой хемилюминесценции, то у больных с тяжелой степенью ВП ГР осуществляет отрицательное каноническое взаимодействие с параметрами спонтанной люминол-зависимой хемилюминесценции. ГР - фермент глутатион-зависимой антиоксидантной системы, которая играет важную роль в регуляции клеточного редокс-потенциала [12]. Повышение канонического веса данного фермента определяет значимость антиоксидантной системы на состояние «респираторного взрыва».

\section{Заключение}

Таким образом, у больных ВП повышен уровень «респираторного взрыва» в нейтрофилах. При этом интенсивность синтеза первичных АФК незначительно зависит от степени тяжести заболевания. Синтез вторичных АФК во многом зависит от степени тяжести ВП. В состоянии относительного покоя нейтрофилов уровень синтеза вторичных АФК у больных с тяжелой степенью ВП ниже, чем при средней степени заболевания. При дополнительной индукции «респираторного взрыва» различия в синтезе вторичных АФК в зависимости от тяжести ВП теряются. При исследовании метаболизма нейтрофилов обнаружено, что только у больных с тяжелой степенью ВП в клетках повышена интенсивность терминальных реакций анаэробного гликолиза и цикла трикарбоновых кислот: отмечается достоверное повышение активности НАДН-ЛДГ и МДГ в нейтрофилах крови у больных с тяжелым течением в сравнении с ВП средней степени. Независимо от тяжести ВП в нейтрофильных гранулоцитах наблюдается повышенная активность липидного анаболизма и отток субстратов с лимонного цикла через НАДН-зависимую глутаматдегидрогеназу. С помощью канонического анализа исследован вклад исследуемых ферментативных реакций в реализацию «респираторного взрыва» в нейтрофильных гранулоцитах в зависимости от степени тяжести ВП. Сбалансированность метаболических процессов в нейтрофилах у здоровых людей определяет участие всех исследуемых оксидоредуктаз в канонической зависимости с показателями хемилюминесцентной активности нейтрофилов. Выявленные изменения активности некоторых ферментов в нейтрофилах у больных с различной степенью тяжести ВП характеризует нарушение ряда метаболических процессов, что обусловливает участие только определенных оксидоредуктаз в канонической зависимости с показателями «респираторного взрыва». Более того, у больных со средней степенью тяжести ВП канонической взаимосвязи исследуемых ферментов с показателями индуцированной люминол-зависимой хемилюминесценции нейтрофилов не обнаружено, так же как и для больных с тяжелой степенью ВП с показателями спонтанной люминол-зависимой хемилюминесценции. Охарактеризованные нарушения метаболических механизмов, определяющих интенсивность «респираторного взрыва» нейтрофилов у больных с различной тяжестью ВП, обусловливают необходимость разработки патогенетически обоснованной терапии, направленной на восстановление основных метаболических процессов фагоцитов и, соответственно, их функции. Высокий уровень активности НАДН-ЛДГ и МДГ, а также низкий уровень хемилюминесцентной активности нейтрофилах крови являются дополнительными маркерами тяжелого течения ВП.

\section{Литература}

1. Чучалин А.Г., Синопальников А.И., Козлов Р.С. и др. Внебольничная пневмония у взрослых: рекомендации по диагностике, лечению и профилактике: Пособие для врачей. М.: РPO, МАKMAX; 2010.

2. Синопальников А.И., Козлов Р.С. Внебольничные инфекции дыхательных путей: Руководство для врачей. М.: Премьер МТ, Наш Город; 2007.

3. Куртасова Л.М., Савченко А.А., Шкапова Е.А. Клинические аспекты функциональных нарушений нейтрофильных гранулоцитов при онкопатологии. Новосибирск: Наука; 2009.

4. Савченко А.А., Здзитовецкий Д.Э., Борисов А.Г., Лузан Н.А. Хемилюминесцентная и энзиматическая активность нейтрофильных гранулоцитов у больных распространенным гнойным перитонитом в зависимости от исхода заболевания. Вестник РАМН. 2014; 5-6: $23-28$.

5. Dinauer M.C. Disorders of neutrophil function: an overview. Methods Mol. Biol. 2014; 1124: 501-515.

6. Ярилин А.А. Иммунология. М.: ГЭОТАР-Медиа; 2010.

7. Liu G., Yang H., Chen X. et al. Modulation of neutrophil development and homeostasis. Curr. Mol. Med. 2013; 13 (8): $1270-1283$.

8. American Thoracic Society, Infectious Diseases Society of America. Guidelines for the management of adults with hospital-acquired, ventilator-associated, and healthcareassociated pneumonia. Am. J. Respir. Crit. Care Med. 2005; 171 (4): 388-416.

9. Chroneou A., Zias N., Beamis J.F., Craven D.E. Healthcare-associated pneumonia: principles and emerging concepts on management. Exp. Opin. Pharmacother. 2007; 8 (18): 3117-3131.

10. Дворецкий Л.И. Внебольничная пневмония: диагностика и антибактериальная терапия. Consilium Medicum. 2008; 3: 25-30.

11. Савченко А.А. Определение активности $\mathrm{NAD}(\mathrm{P})$-зависимых дегидрогеназ в нейтрофильных гранулоцитах биолюминесцентным методом. Бюллетень экспериментальной биологии и медицины. 2015; 159 (5): 656-660.

12. Чиркин А.А., Данченко Е.О. Биохимия. М.: Медицинская литература; 2010.

13. Владимиров Ю.А., Проскурина Е.В. Свободные радикалы и клеточная хемилюминесценция. Успехи биологической химии. 2009; 49: 341-388.

14. Соодаева С.К. Свободнорадикальные механизмы повреждения при болезнях органов дыхания. Пульмонология. 2012; 1: 5-10. 
15. Genestet C., Le Gouellec A., Chaker H. et al. Scavenging of reactive oxygen species by tryptophan metabolites helps Pseudomonas aeruginosa escape neutrophil killing. Free Radic. Biol. Med. 2014; 73: 400-410.

16. Kotzamanis K., Angulo A. Ghazal P. Infection homeostasis: implications for therapeutic and immune programming of metabolism in controlling infection. Med. Microbiol. Immunol. 2015; 204 (3): 395-407.

17. Liu X., Yang Z., Chen Z. et al. Effects of the suppression of lactate dehydrogenase $\mathrm{A}$ on the growth and invasion of human gastric cancer cells. Oncol. Rep. 2015; 33 (1): 157-162.

18. Bao Y., Ledderose C., Seier T. et al. Mitochondria regulate neutrophil activation by generating ATP for autocrine purinergic signaling. J. Biol. Chem. 2014; 289 (39): 26794-26803.

19. Pliyev B.K., Ivanova A.V., Savchenko V.G. Extracellular $\mathrm{NAD}(+)$ inhibits human neutrophil apoptosis. Apoptosis. 2014; 19 (4): 581-593.

20. Nagasaki H., Nakashima A., Kaneko Y.S. et al. Aripiprazole increases NADPH level in PC12 cells: the role of NADPH oxidase. J. Neural. Transm. 2014; 121 (1): 91-103.

Поступила 08.07.15 удк 616.24-002-07:616.155.34-074

\section{References}

1. Chuchalin A.G., Sinopal'nikov A.I., Kozlov R.S. et al. Community-acquired pneumonia in adults: guidelines on diagnosis, treatment and prevention. Moscow: RRO, MAKMAKh; 2010 (in Russian).

2. Sinopal'nikov A.I., Kozlov R.S. Community-acquired respiratory infections. Practical handbook. Moscow: Prem'er MT, Nash Gorod; 2010 (in Russian).

3. Kurtasova L.M., Savchenko A.A., Shkapova E.A. Clinical aspects of functional abnormalities of neutrophil granulocytes in malignancies. Novosibirsk: Nauka; 2009 (in Russian).

4. Savchenko A.A., Zdzitovetskiy D.E., Borisov A.G., Luzan N.A. Chemiluminescent and enzymatic activity of neutrophil granulocytes in patients with extended purulent peritonitis. Vestnik RAMN. 2014; 5-6: 23-28 (in Russian).

5. Dinauer M.C. Disorders of neutrophil function: an overview. Methods Mol. Biol. 2014; 1124: 501-515.

6. Yarilin A.A. Immunology. Moscow: GEOTAR-Media; 2010 (in Russian).

7. Liu G., Yang H., Chen X. et al. Modulation of neutrophil development and homeostasis. Curr. Mol. Med. 2013; 13 (8): $1270-1283$

8. American Thoracic Society, Infectious Diseases Society of America. Guidelines for the management of adults with hospital-acquired, ventilator-associated, and healthcareassociated pneumonia. Am. J. Respir. Crit. Care Med. 2005; 171 (4): 388-416.

9. Chroneou A., Zias N., Beamis J.F., Craven D.E. Healthcare-associated pneumonia: principles and emerging concepts on management. Exp. Opin. Pharmacother. 2007; 8 (18): $3117-3131$

10. Dvoretskiy L.I. Community-acquired pneumonia: diagnosis and antibacterial therapy. Consilium Medicum. 2008; 3: 25-30 (in Russian).

11. Savchenko A.A. Assessment of NADP-dependent dehydrogenase activity in neutrophil granulocytes using a bioluminescent method. Byulleten' eksperimental'noy biologii i meditsiny. 2015; 159 (5): 656-660 (in Russian).
12. Chirkin A.A., Danchenko E.O. Biochemistry. Moscow: Meditsinskaya literatura; 2010 (in Russian).

13. Vladimirov Yu.A., Proskurina E.V. Free radicals and cell chemiluminescence. Uspekhi biologicheskoy khimii. 2009; 49: 341-388 (in Russian).

14. Soodaeva S.K. Free radical-related mechanisms of injury in respiratory diseases. Pul'monologiya. 2012; 1: 5-10 (in Russian).

15. Genestet C., Le Gouellec A., Chaker H. et al. Scavenging of reactive oxygen species by tryptophan metabolites helps Pseudomonas aeruginosa escape neutrophil killing. Free Radic. Biol. Med. 2014; 73: 400-410.

16. Kotzamanis K., Angulo A. Ghazal P. Infection homeostasis: implications for therapeutic and immune programming of metabolism in controlling infection. Med. Microbiol. Immunol. 2015; 204 (3): 395-407.

17. Liu X., Yang Z., Chen Z. et al. Effects of the suppression of lactate dehydrogenase $\mathrm{A}$ on the growth and invasion of human gastric cancer cells. Oncol. Rep. 2015; 33 (1): $157-162$.

18. Bao Y., Ledderose C., Seier T. et al. Mitochondria regulate neutrophil activation by generating ATP for autocrine purinergic signaling. J. Biol. Chem. 2014; 289 (39): 26794-26803.

19. Pliyev B.K., Ivanova A.V., Savchenko V.G. Extracellular $\mathrm{NAD}(+)$ inhibits human neutrophil apoptosis. Apoptosis. 2014; 19 (4): 581-593.

20. Nagasaki H., Nakashima A., Kaneko Y.S. et al. Aripiprazole increases NADPH level in PC12 cells: the role of NADPH oxidase. J. Neural. Transm. 2014; 121 (1): 91-103.

Received July 08, 2015 UDC 616.24-002-07:616.155.34-074

\section{Информация об авторах}

Савченко Андрей Анатольевич - д. м. н., профессор, руководитель лаборатории молекулярно-клеточной физиологии и патологии ФГБНУ «НИИ медицинских проблем Севера», зав. кафедрой физиологии им. проф. А.Т.Пшоника ГБОУ ВПО «Красноярский государственный медицинский университет им. проф. В.Ф.Войно-Ясенецкого» Минздрава России; тел.: (391) 212-52-63, факс: (391) 228-06-83; e-mail: aasavchenko@yandex.ru

Гринштейн Юрий Исаевич - д. М. Н., профессор, зав. кафедрой терапии ИПО ГБОУ ВПО «Красноярский государственный медицинский университет им. проф. В.Ф.Войно-Ясенецкого» Минздрава России тел.: (391) 242-46-64; e-mail: grinstein.yi@mail.ru

Дресвянкина Любовь Викторовна - младший научный сотрудник лаборатории молекулярно-клеточной физиологии и патологии ФГБНУ «НИИ медицинских проблем Севера»; тел.: (391) 212-52-63, факс: (391) 228-06-83; e-mail: lyubov filon@mail.ru

Аристов Александр Иванович - ассистент кафедры терапии ИПО ГБОУ ВПО «Красноярский государственный медицинский университет им. проФ. В.Ф.Войно-Ясенецкого» Минздрава России; тел.: (391) 295-52-26; e-mail: aiaristov@yandex.ru

\section{Author information}

Savchenko Andrey Anatol'evich, MD, Professor, Head of Laboratory of Molecular Physiology and Pathology, Federal Research Institute of Medica Problems of the North; Head of A T.Pshonik Department of Physiology, V.F.Voyno-Yasenetskiy Krasnoyarsk State Medical University, Healthcare Ministry of Russia; tel.: (391) 212-52-63, fax: (391) 228-06-83; e-mail: aasavchenko@yandex.ru

Grinshteyn Yuriy Isaevich, MD, Professor, Head of Department of Therapy, Physician Postgraduate Education Faculty, V.FVoyno-Yasenetskiy Krasnoyarsk State Medical University, Healthcare Ministry of Russia; tel.: (391) 242-46-64; e-mail: grinstein.yi@mail.ru

Dresvyankina Lyubov' Viktorovna, Junior Researcher at Laboratory of Molecular Physiology and Pathology, Federal Research Institute of Medical Problems of the North; V.F.Voyno-Yasenetskiy Krasnoyarsk State Medical University, Healthcare Ministry of Russia; tel.: (391) 212-52-63, fax: (391) 228-06-83; e-mail: Iyubov filon@mail.ru

Аристов Александр Иванович - ассистент кафедры терапии ИПо гБоУ ВПО «Красноярский государственный медицинский университет им. проФ. В.Ф.Войно-Ясенецкого» Минздрава России; тел.: (391) 29552-26; e-mail: aiaristov@yandex.ru 